\title{
Area variation in recreational cycling in Melbourne: a compositional or contextual effect?
}

C B M Kamphuis, K Giskes, A M Kavanagh, L E Thornton, L R Thomas, F J van Lenthe, J P Mackenbach and G Turrell

J Epidemiol Community Health 2008;62;890-898

doi:10.1136/jech.2007.067116

Updated information and services can be found at:

http://jech.bmj.com/cgi/content/full/62/10/890

These include:

References This article cites 26 articles, 10 of which can be accessed free at: http://jech.bmj.com/cgi/content/full/62/10/890\#BIBL

Rapid responses You can respond to this article at:

http://jech.bmj.com/cgi/eletter-submit/62/10/890

Email alerting Receive free email alerts when new articles cite this article - sign up in the box at service the top right corner of the article

Notes

To order reprints of this article go to:

http://journals.bmj.com/cgi/reprintform

To subscribe to Journal of Epidemiology and Community Health go to:

http://journals.bmj.com/subscriptions/ 


\title{
Area variation in recreational cycling in Melbourne: a compositional or contextual effect?
}

\author{
C B M Kamphuis, ${ }^{1}$ K Giskes, ${ }^{1,2}$ A M Kavanagh, ${ }^{3}$ L E Thornton, ${ }^{3}$ L R Thomas, ${ }^{3} \mathrm{~F} J$ van \\ Lenthe, ${ }^{1} \mathrm{~J}$ P Mackenbach, ${ }^{1}$ G Turrell ${ }^{2}$
}

${ }^{1}$ Department of Public Health, Erasmus University Medical Centre, Rotterdam, The Netherlands; ${ }^{2}$ School of Public Health, Institute for Health and Biomedical Innovation, Queensland University of Technology, Brisbane, Australia; ${ }^{3}$ Key Centre for Women's Health in Society, University of Melbourne, Melbourne, Australia

Correspondence to:

Ms C Kamphuis, Department of

Public Health, Erasmus

University Medical Centre, P.O.

Box 2040, 3000 CA Rotterdam,

The Netherlands; c.kamphuis@ erasmusmc.nl

Accepted 1 January 2008

\section{ABSTRACT}

Objective: To examine whether compositional and/or contextual area characteristics are associated with area socioeconomic inequalities and between-area differences in recreational cycling.

Setting: The city of Melbourne, Australia.

Participants: 2349 men and women residing in 50 areas (58.7\% response rate).

Main outcome measure: Cycling for recreational purposes (at least once a month vs never).

Design: In a cross-sectional survey participants reported their frequency of recreational cycling. Objective area characteristics were collected for their residential area by environmental audits or calculated with Geographic Information Systems software. Multilevel logistic regression models were performed to examine associations between recreational cycling, area socioeconomic level, compositional characteristics lage, sex, education, occupation) and area characteristics (design, safety, destinations or aesthetics).

Results: After adjustment for compositional characteristics, residents of deprived areas were less likely to cycle for recreation (OR 0.66; $95 \% \mathrm{Cl} 0.43$ to 1.00 ), and significant between-area differences in recreational cycling were found (median odds ratio 1.48 (95\% credibility interval 1.24 to 1.78). Aesthetic characteristics tended to be worse in deprived areas and were the only group of area characteristics that explained some of the area deprivation differences. Safety characteristics explained the largest proportion of between-area variation in recreational cycling.

Conclusion: Creating supportive environments with respect to safety and aesthetic area characteristics may decrease between-area differences and area deprivation inequalities in recreational cycling, respectively.

People with a lower socioeconomic status (SES) are less physically active than their higher status counterparts, ${ }^{1-3}$ and this has been suggested as one of the explanations for their poorer health and higher mortality rates. ${ }^{4}$ Multilevel studies have documented that disparities in physical activity also exist according to area socioeconomic deprivation (area SES), even after adjustment for individual SES. ${ }^{25-7}$ These findings suggest that deprived areas may be disadvantaged with respect to area characteristics that influence physical activity, independently of the characteristics of the people living in these areas (ie contextual vs compositional effects). ${ }^{89}$

The mechanisms underlying area effects on physical activity are not well understood. Often, multilevel studies have been criticised because they tend to be driven by what data are available (ie, routinely collected data, or individual-level data aggregated to the area level) rather than objectively and systematically collected environmental characteristics. More theory-driven analyses are needed that link environmental features to specific types of physical activity (eg, presence of cycle paths with cycling for transport). ${ }^{10} 11$

Cycling is a moderately intense type of physical activity that, compared with more vigorous forms of exercise, can be incorporated into one's daily routine relatively easy, for multiple purposes (ie recreation, transportation), and at relatively low cost. ${ }^{12}$ However, in most developed countries the prevalence of cycling is low-eg only $8 \%$ and $3 \%$ of Australian adults cycle at least once a week for recreation and transport, respectively. ${ }^{13}$ Meanwhile, in some European countries, cycling levels are much higher (in the Netherlands, for instance, 13\% and $69 \%$ of adults cycle for recreation and transport at least once a week, respectively (Kamphuis and Van den Broek, in preparation), suggesting there are significant opportunities to increase cycling. As small environmental changes may have the potential to lead to substantial and sustainable increases in cycling rates, it is important to understand which area level factors should be the target of public health action.

The current evidence of area influences on cycling mainly comes from the planning and transportation literature and therefore concentrates on cycling for transport. ${ }^{12}{ }^{14-16}$ A review study of area influences on cycling for transport concluded that bike-friendly neighbourhoods are characterised by high population density, a good mixture of land use (ie providing different types of destinations to cycle to, including residential, office, retail/commercial and public space), high connectivity of streets (ie, providing different cycling routes) and adequate design (eg, continuous bike tracks/lanes). ${ }^{17}$ However, evidence about how these factors relate to between-area variation in recreational cycling or to area deprivation inequalities in cycling is limited. ${ }^{718}$

Pikora and colleagues ${ }^{19}$ have previously postulated a framework that includes specific design, safety, destinations and aesthetic characteristics which may influence walking and cycling levels. We examine the extent to which these characteristics explain area deprivation inequalities and between-area variation in recreational cycling, beyond compositional characteristics (ie age, sex, education and occupation).

\section{METHODS}

This study used data from the Victorian Lifestyle and Neighbourhood Environments Study 
(VicLANES), conducted in Melbourne, Australia, in 2003. The aim of VicLANES is to examine associations between environmental factors and socioeconomic inequalities in physical activity, dietary behaviour and alcohol consumption. The study sample included 2349 people residing in 50 census collector districts (CCDs), with a median of 47 respondents per CCD (range 12-92). Further details of the study design and methodology have been reported elsewhere. ${ }^{6}$

\section{Sample areas and population}

The study was conducted in an area extending about 20 kilometres from the central business district in Melbourne. A CCD is the basic geographical unit used by the Australian Bureau of Statistics to collect population census data, with a mean size of $0.34 \mathrm{~km}^{2}$ for the CCDs in our study area. All CCDs in the study area $(n=4170)$ were ranked according to the percentage of households with incomes of less than \$A400 (£195) per week (this income band includes about $15 \%$ of Australian households ${ }^{6}$ ), and then stratified into septiles. Fifty CCDs were randomly selected from this list, ie 17 from the highest, 16 from the middle and 17 from the lowest septile (stage 1). Using the electoral roll (voting is compulsory for Australian adults aged $\geqslant 18$ years), 4005 households were randomly selected and one adult, aged 18-74 years, was randomly selected from each of these households (stage 2). Approximately equal numbers of participants were selected per strata. Selected participants were sent a postal survey. Valid responses were obtained from 2349 persons, giving an overall response rate of $58.7 \%$ (54.6\% in the most disadvantaged septile, $59.0 \%$ in the middle septile and $62.1 \%$ in the most advantaged septile). Participants with missing values for cycling, education and/or occupation $(\mathrm{n}=146)$ were excluded, resulting in $\mathrm{N}=2203$ participants eligible for the analyses.

\section{Outcome measure: recreational cycling}

Two closed-response items assessed participation in cycling and cycling purpose. The first item asked: "How often in the last month did you go cycling for 10 minutes or more?" We asked for cycling for more than 10 minutes, as we wanted respondents to recall substantial cycling episodes during the last month. Participants were asked to nominate one of the following six responses: never, about once or twice, about once a week, 2-3 times a week, 4-5 times a week or every day. The second item asked: "For what purpose do you usually cycle?" with three responses listed: for transport (eg, to get to work, shops), for recreation or exercise or for both transport and recreation. A test-retest of both items over a 2 -week interval on 67 participants showed good reliability (ie weighted kappa's $\mathrm{k}=0.85$ and $\mathrm{k}=0.72$ respectively). The outcome under investigation in the present study was "cycling for recreation": coded as 0, "never"; and 1, "at least once a month".

\section{Area socioeconomic characteristics}

Area socioeconomic level was categorised as high, medium or low, according to the septile from which the CCD was sampled. The mean proportion of households on low income (ie, less than $\$ A 400$ ( $£ 195$ ) per week) ranged from $7.0 \%$ in the high socioeconomic areas to $31.4 \%$ in the low socioeconomic areas.

\section{Objectively measured area characteristics}

All area characteristics and environmental audits were measured at the same time the postal questionnaire was distributed (between September and December-spring/summer in Melbourne). Based on the framework of Pikora and colleagues ${ }^{19}$ we assessed four domains of objective area characteristics, ie design (cycling paths/lanes, streets, street width, alternative routes), safety (lighting, traffic control), destination features (bike parking facilities and destinations such as education institutions, shops (all types), post offices, sport facilities and public transport stops/stations) and aesthetics (streetscape, views, maintenance). These features have been suggested to be related to cycling for recreation by key experts in in-depth interviews and by a Delphi study. ${ }^{19}$

To measure area characteristics, first, we randomly selected a household within each CCD and drew a $400 \mathrm{~m}$ radius around that house, resulting in a $0.50 \mathrm{~km}^{2}$ assessment area. The assessment areas were created using data from CDATA (a census data product from the Australian Bureau of Statistics) ${ }^{20}$ and VicMap datasets, ${ }^{21}$ and MapInfo software. ${ }^{22}$ A cosmetic (picture) layer using electronic street directory of greater Melbourne ('Melways', provided by MapInfo) ${ }^{23}$ was overlaid to facilitate street recognition. All streets within each assessment area were divided into segments, with a segment being the section of a road between two intersections. Figure 1 shows an example of an assessment area with its segments. Each segment was identified with a unique number, resulting in a total of 3054 street segments for the 50 CCDs (average number of segments per CCD was 59, range 23-161).

Auditors carried out an objective environmental audit (including both sides of the street) on each segment by filling in a modified version of the Systematic Pedestrian and Cycling Environmental Scan (SPACES) instrument, which measured characteristics from the Pikora framework. ${ }^{24}$ For each item, segment scores were aggregated to the area level (CCD) by calculating the average score of the segments in the assessment area. Inter-rater and intrarater reliability was conducted among the auditors prior to data collection. Both inter- and intrarater reliability of the items in the instrument have been found to be high in general; ${ }^{24}$ however, in the current investigation 7 of the 31 items (ie path maintenance, path continuity, traffic volume, traffic speed limits, path/lane obstruction, cleanliness, architecture) were excluded from the analyses because of their low inter-rater reliability $(\kappa<0.30)$. We used Melways to calculate the total length of walking and cycling tracks (paths for walking and cycling that were not on a road) and the total area of parks for an area with a $2 \mathrm{~km}$ radius from the centre point of each CCD (see table 2 for details of area characteristics).

\section{Individual characteristics}

Occupation was coded to the Australian Standard Classification of Occupations, and further recoded into professionals (managers, administrators, professionals and paraprofessionals), white-collar employees (clerks, salespersons and service workers) and blue-collar employees (tradespersons, machine operator, drivers, labourers and related workers). A fourth category 'not in labour force' was created for respondents who were retired, studying, unemployed, not looking for work or unable to work. Respondents reported their highest school level completed and any post-school qualifications. Responses were recoded as (1) bachelor degree or higher, (2) diploma (associate or undergraduate), (3) vocational and (4) no post-school qualification. Information on age and sex were obtained from the survey responses or from the electoral roll data if these items were missing. 
Figure 1 Example of an assessment area and its segments.
Lanes-walking audit area: $\mathrm{Hx}$

Melways ref: 71D9 Suburb: wheelers hill Postcode: 3150

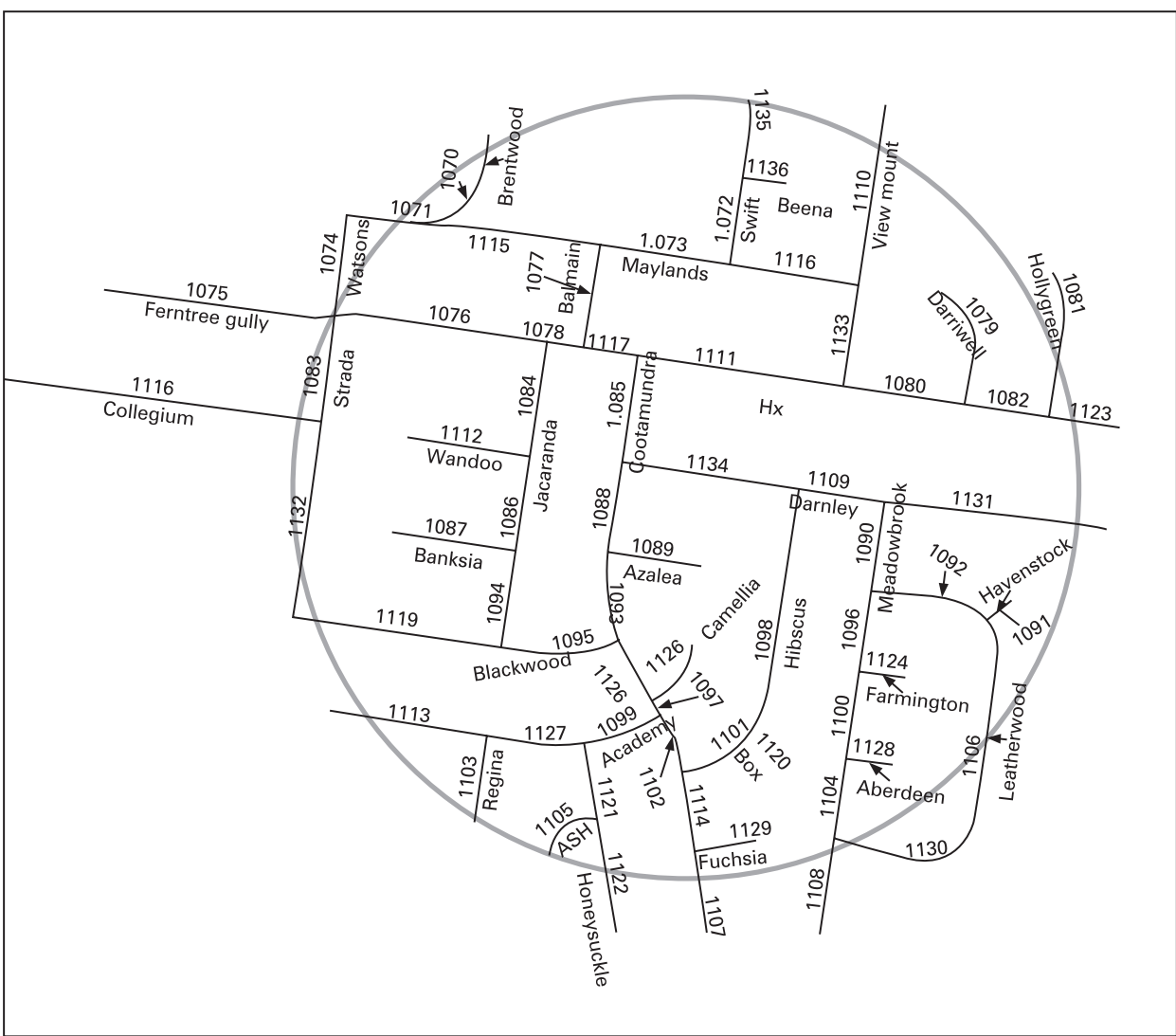

\section{Analyses}

Distributions of individual and area characteristics over high, medium and low socioeconomic areas were investigated with ANOVA, and associations of individual and area characteristics with recreational cycling were conducted using logistic regression models, both in SPSS (version 14). We used MLwiN version 2.02 to examine area deprivation inequalities and between-area differences in recreational cycling. Since recreational cycling was a binary outcome, we performed multilevel logistic analyses using the logit-link function and second-order POL (predictive quasi-likelihood) estimation methods. ${ }^{25}$ Between-area differences in recreational cycling were determined by calculating the median odds ratio (MOR) with $95 \%$ credible intervals (CrI), using the posterior distribution of the area variance as provided by the Markov Chain Monte Carlo (MCMC) procedure in MlwiN. ${ }^{26}$ The intraclass correlation coefficient (ICC) is often calculated for continuous outcomes, and represents the proportion of total variance in the outcome that is attributable to the area level. However, the interpretation of the ICC for dichotomous outcomes is difficult to understand as the individual level variance and the area level variance are not directly comparable. ${ }^{27}$ Therefore, we calculated the MOR instead of the ICC to determine clustering of recreational cycling within areas. The MOR was computed with the following formula: ${ }^{27}$

$$
\begin{aligned}
\mathrm{MOR} & =\exp [\sqrt{ }(2 \times \text { area variance }) \times 0.6745 \\
& \approx \exp (0.95 \sqrt{\text { area variance }})
\end{aligned}
$$

An advantage of the MOR over the between-area variance is its consistent and intuitive interpretation. If the MOR would for instance be 1.50, this shows that in the median case the residual heterogeneity between areas increased by 1.5 times the individual odds of recreational cycling when randomly selecting two persons in different areas-that is, if a person moves to another area with a higher probability of recreational cycling, their odds of engaging in recreational cycling will have a median increase of 1.5 times. $^{27}$

To examine the contributions of different groups of compositional and contextual factors, we used a sequential modelling strategy. First, we fitted a two-level random intercept model without any explanatory variables ("null" model), and then included area SES (model 1). Further, we added sex and age (model 2), and education and occupation (model 3), to examine 
Table 1 Sample (compositional) characteristics by area socioeconomic level, and their associations with recreational cycling $\dagger$

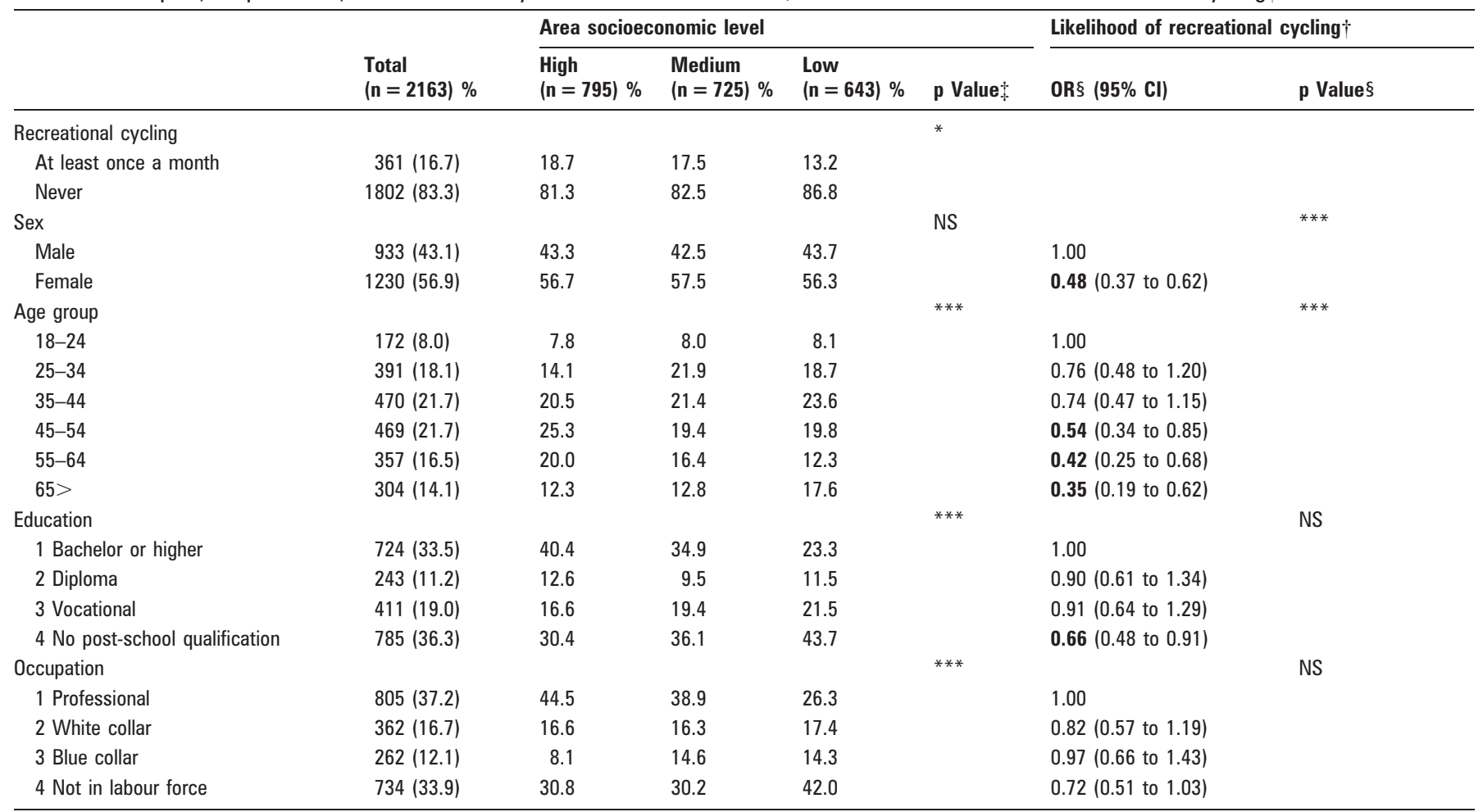

†ikelihood of recreational cycling, "at least once a month" vs "never".

tp Values indicate whether high, medium and low socioeconomic areas have different prevalences of the given characteristics. $p$ Value is based on a $\chi^{2}$ distribution; with NS, not significant; ${ }^{*} \mathrm{p} \leqslant 0.05 ;{ }^{* *} \mathrm{p} \leqslant 0.01 ;{ }^{* * *} \mathrm{p} \leqslant 0.001$.

$\S 0$ dds ratios were adjusted for area socioeconomic level, sex, age, education and occupation. p Values indicate whether characteristics are significantly associated with recreational cycling.

Numbers in bold indicate significant ORs.

to what extent area differences and area socioeconomic variations in recreational cycling could be accounted for by compositional characteristics. Then, we added each of the four groups of area characteristics separately (ie functional, safety, aesthetics and destination; models 4-7), to observe how much of the remaining area differences and area socioeconomic inequalities each group explained (contextual effects). The contribution of explanatory factors to area differences was assessed by reductions in the MOR. The contribution of factors to area socioeconomic inequalities in recreational cycling was assessed by attenuation of the odds ratios for area SES.

\section{FINDINGS}

\section{Cycling}

Of all participants, $81.8 \%(\mathrm{n}=1802)$ reported no cycling at all in the previous month, whereas $1.8 \%(n=40)$ cycled at least once a month for transportation only, $12.8 \%(n=282)$ for recreation only and $3.6 \%(n=79)$ cycled at least once a month for transport and recreation purposes. Low statistical power did not permit us to investigate cycling for transport in relation to areas and area characteristics, therefore participants cycling for transport only $(n=40)$ were excluded from the analyses. We focused on recreational cycling, with 361 participants who cycled for recreation at least once a month (ie, those cycling for recreation only, plus those cycling for both recreation and transport) and 1802 participants never cycling.

\section{The contribution of compositional characteristics}

Compared with high socioeconomic areas, participants residing in low socioeconomic areas were older, less educated, and a higher proportion did not participate in the labour force (see table 1). Women and older participants were significantly less likely to cycle for recreation than men and younger participants. Participants with no post-school qualification (OR 0.66; 95\% CI 0.48 to 0.91 ) and those not in the labour force (OR $0.72 ; 95 \% \mathrm{CI}$ 0.51 to 1.03 ) were less likely to cycle than their higher status counterparts (although these differences were not significant).

\section{Influence of contextual characteristics}

As shown in table 2, four of the eight design features were significantly related to recreational cycling, ie presence of an onroad cycle lane, total track length $(\mathrm{km})$, prevalence of traffic control devices and prevalence of alternative routes. Also, two out of six safety features (ie, verge width and absence of driveway crossovers), one out of three destination features (ie prevalence of destinations) and two out of seven aesthetic features (ie, total park area and lack of garden maintenance) showed a (borderline) significant association with recreational cycling. Larger verge width and lack of garden maintenance was negatively associated with recreational cycling, whereas the other features showed a positive association.

The prevalence of some features was rather low, such as onroad cycle lanes (on 5\% of the segments) and bike parking facilities (on $2 \%$ of the segments), resulting in odds ratios for recreational cycling with wide confidence intervals. Therefore, these characteristics were excluded from subsequent analyses.

The prevalences of three design features (walking/cycling path, cycle lane, path slope) were significantly different for high, medium and low socioeconomic areas $(p<0.05)$, with the most favourable scores for the medium socioeconomic areas. Although not significantly different, high socioeconomic areas 
Table 2 Area (contextual) characteristics of assessment areas $(N=50)$ by area socioeconomic level, and associations of area characteristics with recreational cycling (recreational cycling reported by residents of the 50 areas $(N=2163)) \$$

\begin{tabular}{|c|c|c|c|c|c|c|c|c|}
\hline \multirow[b]{2}{*}{ Variables } & \multirow[b]{2}{*}{$\begin{array}{l}\text { Measurement of area } \\
\text { characteristics } \dagger\end{array}$} & \multicolumn{2}{|c|}{ All areas $(N=50)$} & \multicolumn{4}{|c|}{ Area socioeconomic level mean (SD) } & \multirow{2}{*}{ 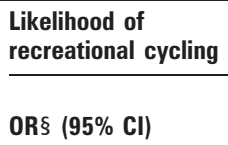 } \\
\hline & & Mean (SD) & Range & $\begin{array}{l}\text { High } \\
(\mathrm{n}=17)\end{array}$ & $\begin{array}{l}\text { Medium } \\
(\mathrm{n}=16)\end{array}$ & $\begin{array}{l}\text { Low } \\
(n=17)\end{array}$ & $\begin{array}{l}\text { p } \\
\text { Value: }\end{array}$ & \\
\hline \multicolumn{9}{|l|}{ Design } \\
\hline \multicolumn{9}{|l|}{ Cycling surface } \\
\hline Path & $\begin{array}{l}\text { Proportions of segments with a } \\
\text { walking/cycling path present }\end{array}$ & $0.83(0.16)$ & $0.20-1.00$ & $0.75(0.20)$ & $0.88(0.13)$ & $0.86(0.12)$ & * & $1.04(0.54$ to 2.00$)$ \\
\hline Cycle lane & $\begin{array}{l}\text { Proportions of segments with an } \\
\text { on-road cycle lane }\end{array}$ & $0.05(0.08)$ & $0.00-0.28$ & $0.06(0.07)$ & $0.09(0.10)$ & $0.01(0.01)$ & * & $5.40(1.29$ to 22.60$)$ \\
\hline Slope & $\begin{array}{l}\text { The degree of incline on walking/ } \\
\text { cycling tracks measured by the } \\
\text { average path slope score } \\
\text { ( } 1=\text { flat/gentle, } 2 \text { = moderate, } \\
3=\text { steep) }\end{array}$ & $1.20(0.30)$ & $1.00-2.60$ & $1.38(0.42)$ & $1.10(0.14)$ & $1.11(0.15)$ & * & $0.87(0.61$ to 1.25$)$ \\
\hline Track length & $\begin{array}{l}\text { Total length of walking/cycling } \\
\text { tracks }(\mathrm{km})\end{array}$ & $15.70(9.95)$ & $3.55-49.87$ & $15.58(7.94)$ & $18.74(14.20)$ & $12.94(5.84)$ & NS & $1.02 \rrbracket(1.01$ to 1.03$)$ \\
\hline \multicolumn{9}{|l|}{ Streets } \\
\hline Width & Average number of lanes on road & $2.65(0.24)$ & $2.00-3.27$ & $2.61(0.25)$ & $2.64(0.14)$ & $2.69(0.29)$ & NS & $0.81(0.49$ to 1.35$)$ \\
\hline Vehicle parking & $\begin{array}{l}\text { Proportions of segments with } \\
\text { vehicle parking restriction signs } \\
\text { present }\end{array}$ & $0.26(0.25)$ & $0.00-0.95$ & $0.23(0.26)$ & $0.31(0.29)$ & $0.25(0.21)$ & NS & $1.52(0.92$ to 2.53$)$ \\
\hline \multicolumn{9}{|l|}{ Traffic } \\
\hline $\begin{array}{l}\text { Traffic control } \\
\text { devices }\end{array}$ & $\begin{array}{l}\text { Proportions of segments with at } \\
\text { least one traffic control device (ie } \\
\text { speed bumps, traffic calming } \\
\text { structures that effect the speed/ } \\
\text { flow of traffic) }\end{array}$ & $0.26(0.14)$ & $0.01-0.62$ & $0.24(0.13)$ & $0.30(0.17)$ & $0.25(0.13)$ & NS & $2.90+\dagger(1.19$ to 7.02$)$ \\
\hline \multicolumn{9}{|l|}{ Alternative routes } \\
\hline Other access points & $\begin{array}{l}\text { Proportions of segments with one } \\
\text { or more other route available (that } \\
\text { provide alternative ways of } \\
\text { cycling around the } \\
\text { neighbourhood) }\end{array}$ & $0.23(0.11)$ & $0.00-0.45$ & $0.23(0.11)$ & $0.22(0.10)$ & $0.23(0.13)$ & NS & $4.49(1.55$ to 13.00$)$ \\
\hline \multicolumn{9}{|l|}{ Safety } \\
\hline \multicolumn{9}{|l|}{ Personal } \\
\hline Lighting & $\begin{array}{l}\text { Proportions of segments with } \\
\text { street lights present }\end{array}$ & $0.56(0.08)$ & $0.40-0.80$ & $0.56(0.07)$ & $0.57(0.11)$ & $0.54(0.07)$ & NS & $0.72(0.17$ to 3.16$)$ \\
\hline Surveillance & $\begin{array}{l}\text { Average surveillance-score } \\
\text { ( } 1=\text { others can observe cyclists } \\
\text { from }<50 \% \text { of buildings, } 2=\text { from } \\
50-75 \% \text { of buildings, } 3=\text { from } \\
>75 \% \text { of buildings) }\end{array}$ & $2.22(0.46)$ & $1.00-2.86$ & $2.14(0.48)$ & $2.25(0.55)$ & $2.25(0.38)$ & NS & $1.11(0.85$ to 1.45$)$ \\
\hline \multicolumn{9}{|l|}{ Traffic } \\
\hline Crossings & $\begin{array}{l}\text { Proportions of segments with one } \\
\text { or more crossings present (eg } \\
\text { zebra, traffic signals, bridge/ } \\
\text { overpass, underpass) }\end{array}$ & $0.07(0.06)$ & $0.00-0.27$ & $0.05(0.05)$ & $0.08(0.07)$ & $0.08(0.05)$ & NS & $0.32(0.02$ to 3.22$)$ \\
\hline Crossing aids & $\begin{array}{l}\text { Proportions of segments with one } \\
\text { or more crossing aids (eg median } \\
\text { refuge, traffic island, kerb } \\
\text { extensions) }\end{array}$ & $0.23(0.14)$ & $0.02-0.58$ & $0.22(0.13)$ & $0.27(0.17)$ & $0.22(0.13)$ & NS & $0.73(0.30$ to 1.78$)$ \\
\hline Verge width & $\begin{array}{l}\text { Average path-location-score } \\
(1=\text { next to road, } 2=<1 \mathrm{~m} \text { from } \\
\text { kerb, } 3=1-2 \mathrm{~m} \text { from kerb, } \\
4=2-3 \mathrm{~m} \text { from kerb, } 5=3>\mathrm{m} \\
\text { from kerb) }\end{array}$ & $3.30(0.92)$ & $1.08-4.58$ & $3.41(0.86)$ & $3.10(1.10)$ & $3.38(0.81)$ & NS & $0.89(0.78$ to 1.01$)$ \\
\hline $\begin{array}{l}\text { Absence of } \\
\text { driveway } \\
\text { crossovers }\end{array}$ & $\begin{array}{l}\text { Average score for driveway- } \\
\text { crossovers ( } 1=\text { most buildings } \\
\text { have driveway, } 2 \text { = half of } \\
\text { buildings have driveway, } \\
3=\text { quarter of buildings have } \\
\text { driveway, } 4=\text { no driveways) }\end{array}$ & $1.61(0.62)$ & $1.00-3.29$ & $1.54(0.49)$ & $1.76(0.83)$ & $1.53(0.49)$ & NS & $1.43(1.18$ to 1.73$)$ \\
\hline \multicolumn{9}{|l|}{ Destinations } \\
\hline Destination present & $\begin{array}{l}\text { Proportion of segments with at } \\
\text { least one destination present }\end{array}$ & $0.40(0.19)$ & $0.12-0.93$ & $0.36(0.15)$ & $0.36(0.21)$ & $0.48(0.19)$ & NS & $1.91(0.99$ to 3.69$)$ \\
\hline Destination variety & $\begin{array}{l}\text { Average number of different } \\
\text { destinations along a segment }\end{array}$ & $0.39(0.27)$ & $0.07-1.28$ & $0.31(0.20)$ & $0.34(0.25)$ & $0.50(0.33)$ & NS & $1.44(0.91$ to 2.27$)$ \\
\hline $\begin{array}{l}\text { Bike parking } \\
\text { facilities }\end{array}$ & $\begin{array}{l}\text { Proportions of segments with bike } \\
\text { parking facilities }\end{array}$ & $0.02(0.03)$ & $0.00-0.13$ & $0.02(0.02)$ & $0.02(0.03)$ & $0.03(0.04)$ & NS & $8.93(0.13$ to 607.8$)$ \\
\hline
\end{tabular}


Table 2 Continued

\begin{tabular}{|c|c|c|c|c|c|c|c|c|}
\hline Variables & $\begin{array}{l}\text { Measurement of area } \\
\text { characteristics } \dagger\end{array}$ & \multicolumn{2}{|c|}{ All areas $(\mathrm{N}=50)$} & \multicolumn{4}{|c|}{ Area socioeconomic level mean (SD) } & $\begin{array}{l}\text { Likelihood of } \\
\text { recreational cycling } \\
\text { OR§ }(95 \% \mathrm{CI})\end{array}$ \\
\hline \multicolumn{9}{|l|}{ Streetscape } \\
\hline Absence of trees & $\begin{array}{l}\text { Average score for trees along the } \\
\text { road }(1=\text { one or more trees per } \\
\text { house block, } 2=\text { one tree for } \\
\text { every } 2 \text { house blocks, } 3=\text { one } \\
\text { tree for every } 3>\text { house blocks, } \\
4=\text { no trees) }\end{array}$ & e $2.06(0.55)$ & $0.68-2.76$ & $2.14(0.48)$ & $2.10(0.64)$ & $1.95(0.55))$ & NS & $0.89(0.72$ to 1.11$)$ \\
\hline $\begin{array}{l}\text { Lack of garden } \\
\text { maintenance }\end{array}$ & $\begin{array}{l}\text { Average score for garden } \\
\text { maintenance }(1=>75 \% \text { well } \\
\text { maintained, } 2=50-75 \% \text { well } \\
\text { maintained, } 3=<50 \% \text { well } \\
\text { maintained) }\end{array}$ & $1.24(0.21)$ & $1.00-1.86$ & $1.14(0.14)$ & $1.22(0.22)$ & $1.36(0.21)$ & NS & $0.55(0.29$ to 1.04$)$ \\
\hline Park area & Total park area $\left(\mathrm{km}^{2}\right)$ & $0.94(0.72)$ & $0.12-3.51$ & $1.10(1.00)$ & $0.98(0.65)$ & $0.73(0.34)$ & NS & 1.26 (1.09 to 1.46$)$ \\
\hline \multicolumn{9}{|l|}{ Views } \\
\hline Urban view & $\begin{array}{l}\text { Proportions of segments with an } \\
\text { urban view (houses, household } \\
\text { gardens) }\end{array}$ & $0.90(0.18)$ & $0.00-1.00$ & $0.93(0.14)$ & $0.89(0.25)$ & $0.89(0.17)$ & NS & $0.85(0.35$ to 2.06$)$ \\
\hline Commercial view & $\begin{array}{l}\text { Proportions of segments with a } \\
\text { commercial view (shops, offices) }\end{array}$ & $0.27(0.22)$ & $0.00-0.80$ & $0.22(0.20)$ & $0.24(0.25)$ & $0.36(0.21)$ & NS & $1.35(0.78$ to 2.33$)$ \\
\hline Natural view & $\begin{array}{l}\text { Proportions of segments with a } \\
\text { natural view (park, lake, river) }\end{array}$ & $0.22(0.17)$ & $0.00-0.67$ & $0.25(0.18)$ & $0.20(0.18)$ & $0.20(0.15)$ & NS & $1.16(0.60$ to 2.26$)$ \\
\hline
\end{tabular}

$\uparrow$ Area characteristics were collected during field observations with the SPACES instrument, except for the total length of tracks and the km ${ }^{2}$ of parks, which were calculated by GIS. $\$$ We used ANOVA to compare the area characteristics among the socioeconomic areas. $\mathrm{p}$ Values indicate whether high, medium and low socioeconomic areas have different prevalences of the given characteristics, with NS, not significant; ${ }^{*} p \leqslant 0.050 ;{ }^{* *} p \leqslant 0.010 ;{ }^{* * *} p \leqslant 0.001$.

$\S 0 d d s$ ratios express the likelihood of recreational cycling (at least once a month vs never). All models included only the predictor variable of interest in the model and were ageadjusted and sex-adjusted. ORs in bold indicate a significant or borderline significant association with recreational cycling.

- Example 1 for interpretation of results: the odds ratio for track length means that for each one unit increase in length (so for each additional kilometre), the odds of recreational cycling increases by $2 \%$.

††Example 2 for interpretation of results: The odds ratio for traffic control devices reflects the effect of an increase in the proportion of segments with traffic control devices from zero (no segment) to $1(100 \%$ of the segments).

had higher scores for most aesthetic features (better garden and verge maintenance, largest park area), but low socioeconomic areas had more destination features (ie higher prevalence and larger variety of destinations).

\section{Between-area differences in recreational cycling}

We found significant between-area differences in recreational cycling for the null model (ie, MOR $=1.49$ (1.26 to 1.77); see table 3 ). The MOR did not change when area socioeconomic level (model 1), and compositional factors (models 2 and 3 ) were added to the null model, and neither changed when design, destination or aesthetic characteristics were separately added to model 3. However, a drop in the MOR was seen when safety features were included ( $\mathrm{MOR}$ reduced to 1.27 (1.03 to 1.60)). Two safety features (surveillance and absence of driveway crossovers) were independently related to recreational cycling.

\section{Area socioeconomic inequalities in recreational cycling}

As presented in table 3, area socioeconomic inequalities remained borderline significant when adjusting for age, sex, education and occupation, with residents of low socioeconomic areas least likely to cycle for recreation (OR 0.65; 95\% CI 0.42 to 1.01). When design, safety, or destination features were added to the model, area socioeconomic inequalities increased marginally. However, area socioeconomic inequalities were attenuated when aesthetic features were added to the model.

\section{DISCUSSION}

\section{Principal findings}

Our study in the city of Melbourne, Australia, showed that there were between-area differences in recreational cycling and that residents of socioeconomically deprived areas were less likely to cycle for recreation, independent of residents' age, sex, occupational and educational level. Safety characteristics partially explained between-area differences in recreational cycling, and poorer aesthetic characteristics in deprived areas made a contribution to explaining the lower rates of engagement in recreational cycling among residents of these areas. Improving the safety and aesthetic characteristics of areas are strategies that may increase recreational cycling.

\section{Study strengths and weaknesses}

This is the first known multilevel study that has investigated a large range of objective area characteristics in relation to recreational cycling and the contribution of those characteristics to area socioeconomic inequalities and between-area differences in recreational cycling. However, this study has a number of limitations. First, it was restricted to a specific geographic area, the city of Melbourne. Therefore, results may only be generalizable to similar areas. Furthermore, audit areas had a $400 \mathrm{~m}$ radius, although cyclists are likely to travel further than $400 \mathrm{~m}$. Someone's immediate surrounding was expected to make a difference for whether people even consider cycling, and, more 


\section{Research report}

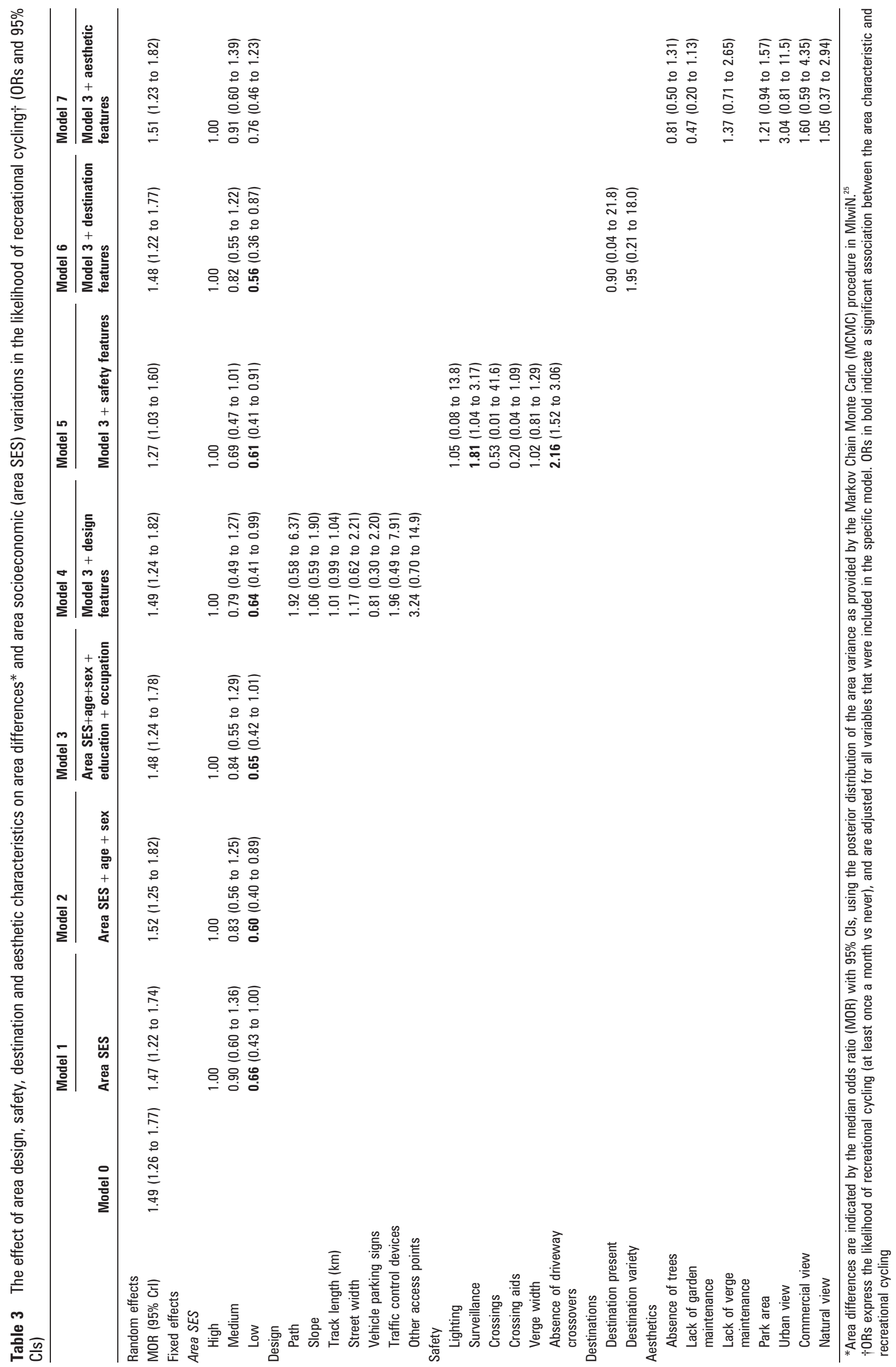


practically, for a data collection method as resource/labour intensive as an environmental audit, this area was the size that we could most cost-effectively collect information. The crosssectional design did not allow us to determine whether area characteristics caused recreational cycling differences or whether residents self-selected into areas according to physical activity opportunities, including bikability. The low prevalence of cycling did not allow us to use a cut-off point of which a larger health impact might be expected, for instance cycling for recreation at least three times per week (instead of at least once a month), nor could we examine transport-related cycling. Additionally, we did not collect information on destinations that participants cycled to. It may be that the design, safety, destination and aesthetic characteristics of areas where participants cycled to were more influential on their recreational cycling than characteristics of their immediate residential areas. Finally, area characteristics were systematically measured with Pikora's SPACES instrument; ${ }^{24}$ however, not all items could be included in the analyses. Some items were excluded because of their low inter-rater reliability (seven items), their low overall prevalence in the assessed areas (two items), or because information on them was not collected (four items). However, we were still able to examine 22 area characteristics, most of which have never been investigated in relation to recreational cycling.

\section{Interpretation of findings}

A previous multilevel paper based on the VicLANES study did not find an association between area socioeconomic level and overall cycling levels. ${ }^{6}$ In contrast, focusing on recreational cycling rather than overall cycling, we did find area socioeconomic variation, showing that area effects may differ even for closely related physical activity outcomes. We found that area socioeconomic inequalities in recreational cycling reduced to non-significance when aesthetic characteristics were taken into account, which is in line with a study from the Netherlands, which found that people residing in the most disadvantaged areas had an increased probability of almost never cycling, walking and gardening for recreation, which was partly mediated by poorer general neighbourhood attractiveness. ${ }^{7}$ Total park area was one of the aesthetic features that showed a significant positive association with recreational cycling (as also found for transportational cycling ${ }^{18}$ ), and decreased with area socioeconomic level (although not significantly). These results are consistent with the literature on perceptions of area characteristics, which has shown that residents of low socioeconomic areas have less positive perceptions of physical activity-related neighbourhood characteristics than residents of high socioeconomic areas. ${ }^{28}$

Although several specific design, destination and aesthetic characteristics were associated with recreational cycling in bivariate associations (adjusted for age and sex), these did not contribute to between-area differences in recreational cycling. This may be due to the areas being relatively uniform in terms of these characteristics. Our findings suggest that some other individual- or area-level factor(s) not considered in the current study contributed to the between-area differences found in recreational cycling. Only safety characteristics explained part of the area differences in recreational cycling, and two specific safety items, surveillance level and absence of driveway crossovers, remained significantly associated with recreational cycling when adjusting for all safety features and compositional factors. This shows that personal as well as traffic safety were independently important for recreational cycling, as had been suggested by the framework developed by Pikora and colleagues. ${ }^{19}$ In contrast, a US study did not find associations between objective measures of traffic or personal safety and combined recreational cycling and walking, ${ }^{29}$ which may be due to, for example, their different safety measure (ie a summary score instead of analysing specific items), their different outcome measure, or because associations between environmental correlates and health behaviours may be country specific. ${ }^{30}$

Area socioeconomic inequalities in recreational cycling actually widened when design, safety or destination characteristics were included in the explanatory model. This is probably due to a suppression effect. ${ }^{31}$ In general, the adjustment of models for explanatory factors (with the highest socioeconomic group being the reference group), leads to a reduction in the magnitude of the inequalities, as explanatory factors are often most favourable for the highest socioeconomic group. However, as we found that some design, safety and destination characteristics were more favourable in low than high socioeconomic areas, adjustment for these factors resulted in a widening of the socioeconomic area inequalities in recreational cycling rather than a decline.

\section{Future research}

The results of this study add to previous findings, confirming the potential role of the built environment on physical activity behaviours. ${ }^{17} 1932$ In future research, causal pathways between area characteristics and transport-related and recreational physical activities should be tested, either in a longitudinal study or in a 'natural experiment' in which activity is measured before and after an environmental modification. Both objective and perceived area characteristics should be investigated, as agreement between the two has found to be small, ${ }^{29}{ }^{33}$ and their relevance for public health action is still under debate.

\section{CONCLUSIONS}

This study provided evidence of significant area differences and socioeconomic area inequalities in recreational cycling that could be explained by some contextual effects, and only marginally by compositional factors. This study also showed that cycling levels are relatively low, also among residents of advantaged areas. Creating supportive neighbourhood environments, especially with respect to aesthetic and safety characteristics may have the potential to increase cycling levels. Lessons could be learned from countries like the Netherlands and Denmark where cycling is extremely popular, and where

\section{What this study adds}

- A recent body of research has demonstrated between-area differences and area deprivation inequalities in physical activity. The mechanisms underlying these area effects on physical activity are not well understood. It is thought that composition and contextual features of areas may contribute to them.

- Our study showed that area variations and area socioeconomic inequalities in recreational cycling existed, even after adjustment for residents' age, sex, occupational and educational level. Safety characteristics explained area differences in recreational cycling and aesthetic characteristics made a contribution to area socioeconomic inequalities in recreational cycling. Creating supportive environments for physical activity may increase population levels of physical activity. 
measures to improve the bikability of cities are readily available. ${ }^{12}$

Acknowledgements: CK is supported by a grant from NWO (Netherlands Organization for Scientific Research), and by a fund of the Trustfonds (Erasmus University Rotterdam, the Netherlands). KG is supported by an Australian National Health and Medical Research Council Sidney Sax Fellowship (ID 290540). GT is supported by an Australian National Health and Medical Research Council Senior Research Fellowship (ID 390109). The VicLANES study was supported by a grant from the Victorian Health Promotion Foundation.

Competing interests: None declared.

Ethics approval: The project was approved by the La Trobe University Human Ethics Committee.

\section{REFERENCES}

1. Droomers M, Schrijvers CT, Mackenbach JP. Educational level and decreases in leisure time physical activity: predictors from the longitudinal GLOBE study. $J$ Epidemiol Community Health 2001;55:562-8.

2. Giles-Corti B, Donovan RJ. Socioeconomic status differences in recreational physical activity levels and real and perceived access to a supportive physical environment. Prev Med 2002;35:601-11.

3. Lindstrom M, Hanson BS, Ostergren PO. Socioeconomic differences in leisure-time physical activity: the role of social participation and social capital in shaping health related behaviour. Soc Sci Med 2001;52:441-51.

4. Lynch JW, Kaplan GA, Cohen RD, et al. Do cardiovascular risk factors explain the relation between socioeconomic status, risk of all-cause mortality, cardiovascular mortality, and acute myocardial infarction? Am J Epidemiol 1996;144:934-42.

5. Sundquist J, Malmstrom M, Johansson SE. Cardiovascular risk factors and the neighbourhood environment: a multilevel analysis. Int J Epidemiol 1999;28:841-5.

6. Kavanagh AM, Goller JL, King T, et al. Urban area disadvantage and physical activity: a multilevel study in Melbourne, Australia. J Epidemiol Community Health 2005;59:934-40.

7. Van Lenthe FJ, Brug J, Mackenbach JP. Neighbourhood inequalities in physical inactivity: the role of neighbourhood attractiveness, proximity to local facilities and safety in the Netherlands. Soc Sci Med 2005;60:763-75.

8. Macintyre S, Maclver S, Sooman A. Area, class and health: should we be focusing on places or people? J Soc Policy 1993;22:213-34.

9. Smith GD, Hart C, Watt G, et al. Individual social class, area-based deprivation, cardiovascular disease risk factors, and mortality: the Renfrew and Paisley Study. J Epidemiol Community Health 1998;52:399-405.

10. Giles-Corti B, Timperio A, Bull F, et al. Understanding physical activity environmental correlates: increased specificity for ecological models. Exerc Sport Sci Rev 2005;33:175-81.

11. Diez Roux AV. Investigating neighborhood and area effects on health. Am J Public Health 2001;91:1783-9.
12. Pucher J, Dijkstra L. Promoting safe walking and cycling to improve public health: lessons from The Netherlands and Germany. Am J Public Health 2003;93:1509-16.

13. McCormack G, Milligan R, Giles-Corti B, et al. Physical activity levels of Western Australian adults 2002: results from the adult physical activity survey and pedometer study. Perth, Western Australia: Western Australian Government 2003.

14. Cervero R, Duncan M. Walking, bicycling, and urban landscapes: evidence from the San Francisco Bay Area. Am J Public Health 2003;93:1478-83.

15. Plaut PO. Non-motorized commuting in the US. Transportation Research Part D 2005; 10:347-56.

16. Vernez Moudon A, Lee C, Cheadle A, et al. Cycling and the built envrionment, a US perspective. Transportation Research Part D 2005;10:245-61.

17. Saelens BE, Sallis JF, Frank LD. Environmental correlates of walking and cycling: findings from the transportation, urban design, and planning literatures. Ann Behav Med 2003;25:80-91.

18. Wendel-Vos GC, Schuit AJ, de Niet R, et al. Factors of the physical environment associated with walking and bicycling. Med Sci Sports Exerc 2004;36:725-30.

19. Pikora T, Giles-Corti B, Bull F, et al. Developing a framework for assessment of the environmental determinants of walking and cycling. Soc Sci Med 2003;56:1693-703.

20. Australian Bureau of Statistics. CDATA 2001 - your census at work (2nd release). Canberra: Australian Bureau of Statistics, 2003.

21. Department of Sustainability and Environment. Vicmaps, Land Information Group Victoria. Melbourne: Department of Sustainability and Environment, 2002.

22. Maplnfo Corporation. Maplnfo Professional version 7.2. New York: Troy, 2002.

23. Melways Greater Melbourne (V30). Mount Waverly: Ausway 2003.

24. Pikora TJ, Bull FC, Jamrozik K, et al. Developing a reliable audit instrument to measure the physical environment for physical activity. Am J Prev Med 2002;23:187-94

25. Rasbash J, Steele F, Browne W, et al. A user's guide to MLwiN Version 2.0. Bristol: Centre for multilevel modelling, University of Bristol, 2005.

26. Browne WJ, Rasbash J, Edmond WS. MCMC estimation in MLwiN version 2.0. Bristol: Centre for multilevel modelling, University of Bristol, 2005.

27. Merlo J, Chaix B, Ohlsson $\mathrm{H}$, et al. A brief conceptual tutorial of multilevel analysis in social epidemiology: using measures of clustering in multilevel logistic regression to investigate contextual phenomena. J Epidemiol Community Health 2006;60:290-7.

28. Wilson DK, Kirtland KA, Ainsworth BE, et al. Socioeconomic status and perceptions of access and safety for physical activity. Ann Behav Med 2004;28:20-8.

29. Hoehner CM, Brennan Ramirez LK, Elliott MB, et al. Perceived and objective environmental measures and physical activity among urban adults. Am J Prev Med 2005;28:105-16.

30. Cummins S, Macintyre S. Food environments and obesity-neighbourhood or nation? Int J Epidemiol 2006;35:100-4.

31. MacKinnon DP, Krull JL, Lockwood CM. Equivalence of the mediation, confounding and suppression effect. Prev Sci 2000;1:173-81.

32. Frank LD, Schmid TL, Sallis JF, et al. Linking objectively measured physical activity with objectively measured urban form: findings from SMARTRAO. Am J Prev Med 2005;28:117-25.

33. McGinn AP, Evenson KR, Herring AH, et al. The relationship between leisure, walking, and transportation activity with the natural environment. Health Place 2007; 13:588-602. 